\title{
Formulation of an Agile Office Product: An Application of Axiomatic Design in Engineering
}

\author{
Christopher Spalding ${ }^{1}$, ZiXiao Wei ${ }^{1}$ and Anthony Yarkov ${ }^{1, *}$ \\ ${ }^{1}$ University of New South Wales, School of Mechanical and Manufacturing Engineering, Randwick, Sydney, Australia
}

\begin{abstract}
Axiomatic Design was applied in an undergraduate student-led project which culminated in the creation of an agile ergonomic monitor stand, a solution designed to optimise the productivity and working conditions of the office environment. The customer domain was determined using a Mendelow's Stakeholder Analysis followed by contextual inquiries and lead user interviews. These customer needs were organised into different levels via Maslow's Hierarchy and redefined in terms of functional requirements. The functional requirements were decomposed and classified using the Kano Customer Satisfaction and Long Tail Models, and ultimately organised into a functional requirement tree. Design constraints were considered and listed, and the customer and functional domains were compared using a House of Quality. This allowed potential design paths to be devised with respect to the chosen functional requirements. The path involving the smart ergonomic stand was chosen from a number of potential products assessed against the functional requirements by listing the potential design parameters in a morphological matrix. Concepts were designed by creating combinations of these design parameters, with their suitability being judged using the Independence Axiom. The physical form of the solution was inspired using biological sources. The final details of the design were chosen using the Information Axiom to determine their suitability in practical implementation allowing the final concept to be produced in a 3D CAD model.
\end{abstract}

\section{Introduction}

Design conceptualisation is a key part of the education of engineering students. Furthermore, the concepts enveloped in Axiomatic Design provide a framework to be applied through the professional career of an engineer in its applicability for engineering design projects. This paper provides an overview of a student led project and its use of Axiomatic Design to formulate the conceptual design of an ergonomic monitor stand based on the selected client brief to create an office product to enhance productivity, increase physical activity, decrease stress or incidences of injury.

As such, this report starts with the design thinking progression beginning with an outline of the procedures used to attain the customer prior to presenting the use of axiomatic design. As such, the transformation of the customer needs to the functional domain and subsequent functional requirement was investigated and flowed into the creation of a broad product category of Workstation Optimisation. An overview is provided, highlighting the processes used to refine this product category to an individual product, the reassessment of the functional requirements and the formation of initial concepts.
Following this, the paper covers the design progression and use of Axiomatic Design through the Independence and Information Axioms to further refine the product concepts. This design refinement used the efficacy Independence Axiom to select the least coupled design, amongst a list of generated concepts, whilst the Information Axiom assessed the applicability of the design parameters against the functional requirements. The report then concludes with a visualisation of the final design defined through the axiomatic design process which is accompanied by a reflection of the design process.

\section{Customer Needs (CNs) and Functional Requirements (FRs)}

\subsection{Determination of Customer Needs (CNs)}

The customer domain research was limited to business users with an initial focus on small to medium sized enterprises. This allowed for focus to be placed on a smaller group of primary stake holders, which was defined using a Mendelow's Stakeholder Analysis, Figure 1. 
The customer needs that defined the final product were ascertained through three contextual inquiries and a lead user interview. Contextual inquiry focused on representatives of key stakeholders, defined as directors, owners, and management while the lead user interview focused on a product evangelist. These four interviewees are a representative sample of the target customers, as they control what solutions are used within the office workplace they command. Whilst end users (i.e. employees) are significant stake holders as they represent the end users of office equipment, compiling a meaningful data set from a large sample space was outside the scope of this particular study. Therefore, the customer needs used to outline the requirements of the key stakeholders are showcased in Table 1.

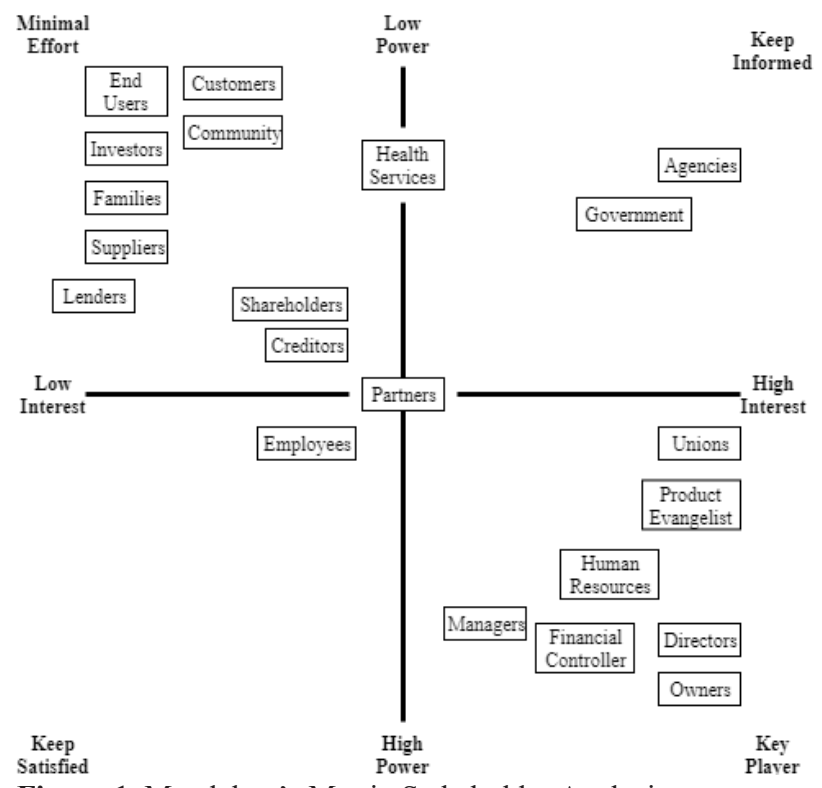

Figure 1. Mendelow's Matrix Stakeholder Analysis

Table 1. Customer Needs

\begin{tabular}{|l|l|l|}
\hline \multicolumn{2}{|l|}{ Customer Need } & Description \\
\hline $\mathrm{CN}_{01}$ & Professional & $\begin{array}{l}\text { The product should look } \\
\text { professional. }\end{array}$ \\
\hline $\mathrm{CN}_{02}$ & Productive & $\begin{array}{l}\text { The product should increase } \\
\text { productivity. }\end{array}$ \\
\hline $\mathrm{CN}_{03}$ & Performance & $\begin{array}{l}\text { The product should perform } \\
\text { better than current } \\
\text { solutions. }\end{array}$ \\
\hline $\mathrm{CN}_{04}$ & Usability & $\begin{array}{l}\text { The product should be } \\
\text { intuitive to use. }\end{array}$ \\
\hline $\mathrm{CN}_{06}$ & Compatible & $\begin{array}{l}\text { The product should easily } \\
\text { integrate into current } \\
\text { products and services } \\
\text { contained within the office } \\
\text { space. }\end{array}$ \\
\hline $\mathrm{CN}_{07}$ & Inclusion & $\begin{array}{l}\text { The product should not only } \\
\text { be reliable on its own but } \\
\text { also in tandem with other } \\
\text { solutions. }\end{array}$ \\
\hline
\end{tabular}

\begin{tabular}{|l|l|l|}
\hline $\mathrm{CN}_{08}$ & Health & $\begin{array}{l}\text { The use of the device should } \\
\text { enhance the health and } \\
\text { wellbeing of the user. }\end{array}$ \\
\hline $\mathrm{CN}_{09}$ & Implementation & $\begin{array}{l}\text { The implementation of the } \\
\text { product should be quick, } \\
\text { well-coordinated, and not } \\
\text { require the redesign or refit } \\
\text { of the office space. }\end{array}$ \\
\hline $\mathrm{CN}_{10}$ & Safe & $\begin{array}{l}\text { The product should not } \\
\text { present occasions of } \\
\text { potential injury. }\end{array}$ \\
\hline
\end{tabular}

The customer needs were then classified as per Maslow's Design Hierarchy as provided in, Figure 2, and listed in Table 2.

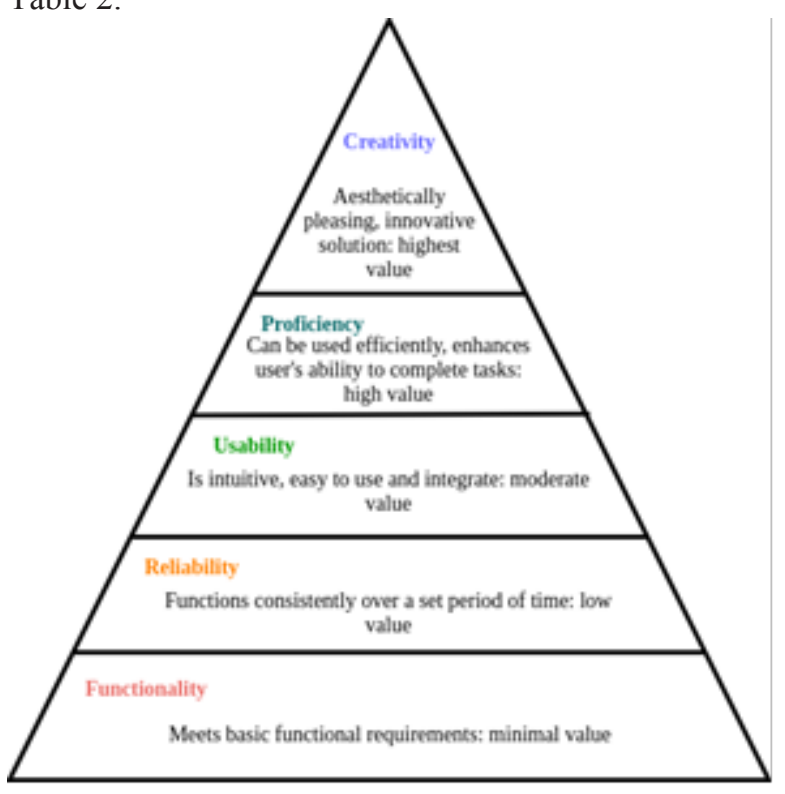

Figure 2. Maslow's Design Hierarchy of Needs

Table 2. Customer Needs classification in accordance to Maslow's Design Hierarchy

\begin{tabular}{|l|l|}
\hline $\begin{array}{l}\text { Maslow's Design } \\
\text { Hierarchy Class }\end{array}$ & Customer Need \\
\hline Creativity & $\mathrm{CN}_{01}$ \\
\hline Proficiency & $\mathrm{CN}_{02}, \mathrm{CN}_{03}$ \\
\hline Usability & $\mathrm{CN}_{04}, \mathrm{CN}_{05}$ \\
\hline Reliability & $\mathrm{CN}_{06}$ \\
\hline Functionality/Safety & $\mathrm{CN}_{07}, \mathrm{CN}_{08}, \mathrm{CN}_{09}, \mathrm{CN}_{10}$ \\
\hline
\end{tabular}

Maslow's Design Hierarchy, Figure 2, was used to prioritise and order the customer needs. As such, the first needs the product needed to address were (functional needs) $\mathrm{CN}_{10}, \mathrm{CN}_{09}, \mathrm{CN}_{08}$, and $\mathrm{CN}_{07}$, followed by (reliability need) $\mathrm{CN}_{06}$, (usability needs) $\mathrm{CN}_{04}, \mathrm{CN}_{05}$, (proficiency needs) $\mathrm{CN}_{02}, \mathrm{CN}_{03}$, and (creativity need) $\mathrm{CN}_{01}$. Fulfillment of the base needs will allow implementation of higher needs as defines a quality product.

\subsection{Extrapolation of Customer Voices}

Employers, especially at the international level, face challenges in attracting the most highly talented job 
applicants. For instance, the undersupply within the information technology sector in Australia results in competition between employers to attract the most competent candidates. One strategy is to create a more desirable office environment by focusing on enhancing employee health, comfort and engagement. An example of improving employee health is the introduction of ergonomic chairs, desks, computer mice, keyboards and monitors. However, the company must take budget constraints into account. The resulting solution produced will ideally be introduced widely amongst businesses with functionality desirable to current and future employees, addressing the health, comfort and engagement of employees.

\subsection{Formulation of Functional Requirements (FRs)}

To allow a solution-neutral approach, the primary functional requirement was defined as $<\mathrm{FR}$ : Optimise Office $>$. This was decomposed into more specific FRs which would best satisfy the customer needs. To address the engagement needs, $<\mathrm{FR}_{1}$ : increase productivity $>$ was decided upon. Employee health were to be improved through $<\mathrm{FR}_{2}$ : reduce workplace related injury $>$, and the budget constraints accounted for using $<\mathrm{FR}_{3}$ : Increase cost effectiveness $>$.

$\mathrm{FR}_{1}, \mathrm{FR}_{2}$ and $\mathrm{FR}_{3}$ were further broken down into more specific FRs that were more powerfully defined, as to provide concrete goals for engineers to achieve, shown in Table 3.

Table 3. FR $1,2,3$ : Mapping of Customer Needs

\begin{tabular}{|c|c|c|c|c|}
\hline \multirow[t]{11}{*}{$\begin{array}{l}\mathbf{F R}_{1}: \quad \text { Increase } \\
\text { productivity }\end{array}$} & \multirow{4}{*}{$\begin{array}{l}\text { FR }_{11} \text { : Increase job } \\
\text { satisfaction }\end{array}$} & $\begin{array}{l}\text { FR 111: Create sense } \\
\text { of achievement }\end{array}$ & & \multirow{4}{*}{$\begin{array}{l}\mathrm{CN}_{02} \\
\mathrm{CN}_{04} \\
\mathrm{CN}_{05} \\
\mathrm{CN}_{06} \\
\mathrm{CN}_{08} \\
\mathrm{CN}_{09}\end{array}$} \\
\hline & & $\begin{array}{l}\text { FR112: } \\
\text { stress }\end{array}$ & $\begin{array}{l}\text { FR1121: Increase } \\
\text { physical activity }\end{array}$ & \\
\hline & & \multirow{2}{*}{$\begin{array}{l}\text { FR }_{113} \text { Improve } \\
\text { workplace } \\
\text { interactions }\end{array}$} & $\begin{array}{l}\text { FR }_{1131}: \text { Facilitate } \\
\text { inclusiveness }\end{array}$ & \\
\hline & & & & \\
\hline & \multirow{7}{*}{$\begin{array}{l}\text { FR }_{12}: \quad \text { Increase } \\
\text { employee comfort }\end{array}$} & \multirow{6}{*}{$\begin{array}{l}\text { FR121: Enhance } \\
\text { environment }\end{array}$} & & \multirow{7}{*}{$\begin{array}{l}\mathrm{CN}_{02} \\
\mathrm{CN}_{03} \\
\mathrm{CN}_{05} \\
\mathrm{CN}_{09}\end{array}$} \\
\hline & & & FR1212: Keep noise & \\
\hline & & & between $10 \mathrm{~dB}-$ & \\
\hline & & & $50 \mathrm{~dB}[1]$ & \\
\hline & & & 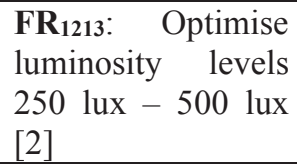 & \\
\hline & & & $\begin{array}{ll}\text { FR1215: } & \text { Improve } \\
\text { aesthetics } & \\
\end{array}$ & \\
\hline & & $\begin{array}{l}\text { FR 122: }_{\text {intary }} \quad \text { Reduce } \\
\text { sedentary periods }\end{array}$ & $\begin{array}{l}\text { FR }_{1221}: \\
\text { Encouraging } \\
\text { varying positions }\end{array}$ & \\
\hline \multirow[t]{3}{*}{$\begin{array}{lr}\text { FR2: } & \text { Reduce } \\
\text { Workplace } & \text { related } \\
\text { injury } & \end{array}$} & $\begin{array}{l}\text { FR21: Improve } \\
\text { Safety }\end{array}$ & & & $\begin{array}{l}\mathrm{CN}_{06} \\
\mathrm{CN}_{08} \\
\mathrm{CN}_{10}\end{array}$ \\
\hline & $\begin{array}{ll}\text { FR22: } & \text { Reduce } \\
\text { Repetitive } & \\
\text { Movement } & \\
\end{array}$ & $\begin{array}{l}\text { FR221: Integrate } \\
\text { Dynamic } \\
\text { Workstation }\end{array}$ & & $\begin{array}{l}\mathrm{CN}_{05} \\
\mathrm{CN}_{07} \\
\mathrm{CN}_{08} \\
\end{array}$ \\
\hline & $\begin{array}{l}\text { FR23: Encourage } \\
\text { Natural Position }\end{array}$ & $\begin{array}{l}\text { FR231: Increase } \\
\text { Ergonomics }\end{array}$ & & $\begin{array}{l}\mathrm{CN}_{03} \\
\mathrm{CN}_{07} \\
\mathrm{CN}_{08}\end{array}$ \\
\hline \multirow[t]{4}{*}{$\begin{array}{l}\mathbf{F R}_{\mathbf{3}} \text { : Increase Cost } \\
\text { Effectiveness }\end{array}$} & \multirow{2}{*}{$\begin{array}{l}\text { FR31: Enhance } \\
\text { Reliability }\end{array}$} & $\begin{array}{l}\text { FR311: Decrease } \\
\text { Maintenance } \\
\text { Requirements }\end{array}$ & & $\begin{array}{l}\mathrm{CN}_{03} \\
\mathrm{CN}_{06}\end{array}$ \\
\hline & & $\begin{array}{l}\text { FR }_{\mathbf{3 1 2}} \text { : Increase } \\
\text { Product Lifespan }\end{array}$ & & \\
\hline & $\begin{array}{l}\text { FR } \mathbf{R}_{\mathbf{3 2}} \text { Improve } \\
\text { Resources } \\
\text { Management }\end{array}$ & $\begin{array}{l}\text { FR321: Improve } \\
\text { Product Utilisation }\end{array}$ & & $\begin{array}{l}\mathrm{CN}_{02} \\
\mathrm{CN}_{05} \\
\mathrm{CN}_{09} \\
\end{array}$ \\
\hline & $\begin{array}{l}\text { FR33: Optimise } \\
\text { Operational } \\
\text { Processes }\end{array}$ & $\begin{array}{l}\text { FR 331: Increase } \\
\text { Ergonomics }\end{array}$ & $\begin{array}{l}\text { FR3311: Reduce } \\
\text { Complexity }\end{array}$ & $\begin{array}{l}\mathrm{CN}_{04} \\
\mathrm{CN}_{05} \\
\mathrm{CN}_{09}\end{array}$ \\
\hline
\end{tabular}




\subsection{Classification of Functional Requirements}

The FRs can be categorised using the Kano Customer Satisfaction model in Figure 3, and the Long Tail model in Figure 4.

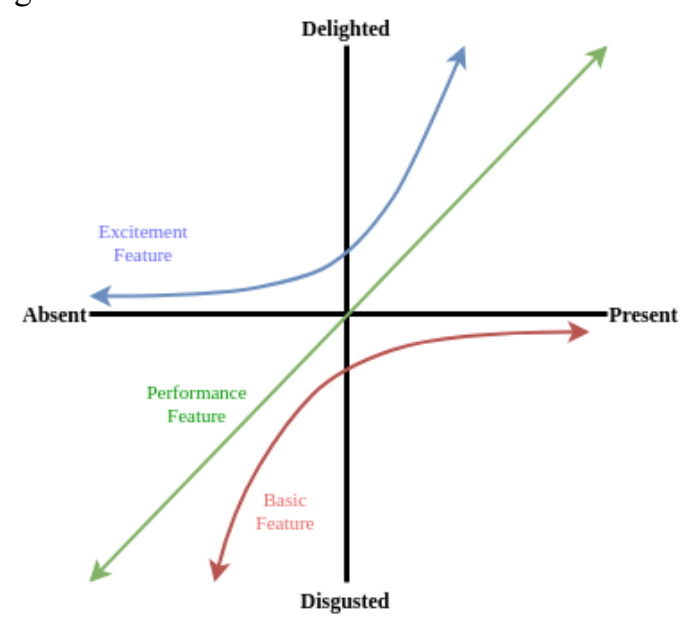

Figure 3. Kano Customer Satisfaction Model

The Kano Customer Satisfaction model ranks features of the design solution by comparing the effect of public perception in relation to the presence (or absence) of specific features. The functional requirements of the solution are designated as:

- $\quad$ Basic (B): essential, expected

- Performance (P): recommended, present on the most competitive solutions

- Excitement (E): unexpected, non-essential but greatly beneficial if present

The FR's as outlined above were classified as The FR's as outlined above where classified as per the Kano Customer Model, Figure 3, and are tabulated in Table 4. Functional Requirements as classified by Kano Customer Satisfaction Model.

This method was used to identify the weighted importance of specific functions to ensure the basic requirements were satisfied first which is essential for a successful solution. In this instance, the FRs at the third level of decomposition are analysed here as they are the most explicitly defined.

Table 4. Functional Requirements as classified by Kano Customer Satisfaction Model

\begin{tabular}{|c|c|c|}
\hline $\begin{array}{l}\text { Functional } \\
\text { Requirement }\end{array}$ & $\begin{array}{l}\text { Kano } \\
\text { Classification }\end{array}$ & Reasoning \\
\hline FR $_{1121}$ & $\mathrm{P}$ & Healthy workers are typically more motivated and therefore more productive. [3] \\
\hline FR1131 $_{11}$ & $\mathrm{E}$ & $\begin{array}{l}\text { An inclusive solution that allows workers to feel a part of a community can increase } \\
\text { productivity as their input is more readily considered. }\end{array}$ \\
\hline $\mathbf{F R}_{1212}$ & $\mathrm{~B}$ & $\begin{array}{l}\text { It is very difficult for employees to concentrate on mental tasks if the ambient noise } \\
\text { level is very high [4]. }\end{array}$ \\
\hline $\mathbf{F R}_{1213}$ & $\mathrm{P}$ & $\begin{array}{l}\text { Optimisation of light levels reduces eye strain in employees and therefore reduces } \\
\text { instances of sick leave [5]. }\end{array}$ \\
\hline $\mathbf{F R}_{1215}$ & $\mathrm{P}$ & $\begin{array}{l}\text { A solution that is sensually pleasant will have some positive effect on the } \\
\text { psychological wellbeing of the worker. }\end{array}$ \\
\hline $\mathbf{F R}_{1221}$ & $\mathrm{P}$ & $\begin{array}{l}\text { Employees are less prone to repetitive strain injury if they have some freedom in } \\
\text { their working positions [3]. }\end{array}$ \\
\hline FR3311 & $\mathrm{P}$ & Less complex solutions are easier to integrate, reducing productivity loss. \\
\hline
\end{tabular}

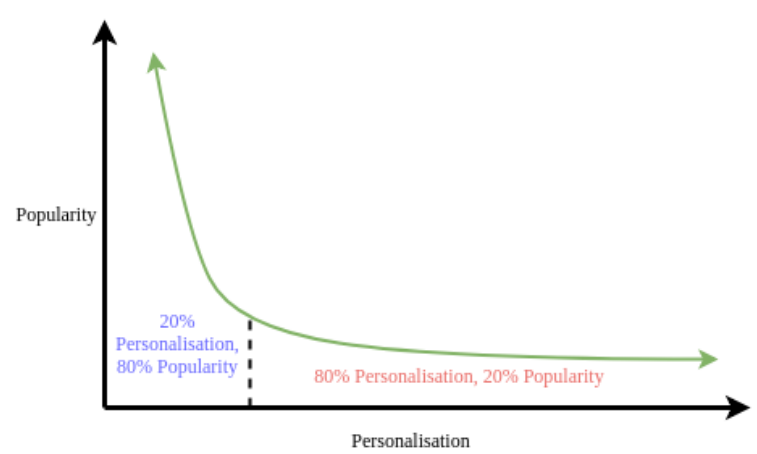

Figure 4. Long Tail Model
The Long Tail model, Figure 4, compares features by their popularity in relation to their availability within existing solutions. The functional requirements can be rated as either:

- Popular (P)

- Unpopular (U)

The Long Tail model indicates the prevalence of the FR's in the marketplace within competitors' solutions in

Table 5. Functional Requirements as classified by Long Tail Model. The likelihood of an employer already having a solution for a specific functional requirement was ascertained through interviews with key stakeholders. 
Table 5. Functional Requirements as classified by Long Tail Model

\begin{tabular}{|c|c|c|}
\hline $\begin{array}{l}\text { Functional } \\
\text { Requirement }\end{array}$ & $\begin{array}{l}\text { Long Tail } \\
\text { Classification }\end{array}$ & Reasoning \\
\hline FR $_{1121}$ & $\mathrm{P}$ & $\begin{array}{l}\text { Modern businesses are aware of the importance of worker health and have therefore } \\
\text { taken measures to address this. }\end{array}$ \\
\hline FR $_{1131}$ & $\mathrm{P}$ & $\begin{array}{l}\text { Modern businesses already take measures to integrate employees into the work } \\
\text { environment }\end{array}$ \\
\hline FR $_{1212}$ & $\mathrm{P}$ & $\begin{array}{l}\text { Many offices already have well understood the importance of noise control and have } \\
\text { measures in place }\end{array}$ \\
\hline FR $_{1213}$ & $\mathrm{U}$ & Many workplaces have generic lighting systems which do not offer much control \\
\hline FR 1215 & $\mathrm{P}$ & $\begin{array}{l}\text { Many product solutions try to be aesthetically pleasing to help differentiate them from } \\
\text { the merely functional competitors }\end{array}$ \\
\hline FR $_{1221}$ & $\mathrm{U}$ & $\begin{array}{l}\text { Most office environments require sitting in a chair in a fixed position for extended } \\
\text { periods of time [3] }\end{array}$ \\
\hline FR3311 & $\mathrm{P}$ & $\begin{array}{l}\text { Most companies are not willing to spend more time or resources than necessary to } \\
\text { implement new solutions }\end{array}$ \\
\hline
\end{tabular}

\subsection{Functional Requirement Organisation}

The main functional requirement (Optimise Office), was decomposed into focussed functional requirements as shown in Figure 13, Appendix.

\subsection{Design Constraints}

Functional solutions need to comply to defined constraints in order to be feasible. In this context the following constraints were identified:

Cost: The solution must not be prohibitively expensive to implement and should be cost competitive with products with similar functions. Factors that affect this include the supply and selection of materials used and manufacturing setup and maintenance expenses.

Time: The solution needs to be implementable in a relatively short time frame to reduce productivity loss.

Space: The solution needs to fit within the size constraints of existing solutions and use the given space efficiently.

\subsection{Customer and Functional Domain Mapping}

The strength of correlation between the customer needs and functional requirements was defined using a House of Quality (HoQ). This was done to determine which FRs were to be prioritised.

The most important FRs were found to be in relation to health and organisation: (reduce safety hazards [14.9\%]), followed by (reduce complexity [10.2\%]), and (ergonomics [8.7\%]).

It was found that increasing physical activity was found to negatively correlate with safety hazard reduction, suggesting that this design choice was inadvisable. Lack of correlation between ergonomics and organisation suggests that it would be difficult to create a design that satisfied both conditions.

Positive relationships between ergonomics, workspace dynamism and posture variation implied that a solution geared towards reducing repeated stress injury (RSI) would be wise to develop without being excessively difficult to implement.

Another positive relationship between reduced complexity and task organisation highlighted another design path, for example providing a task tracking tool.

\section{Concept Ideation (FR-DP Mapping)}

The concept design started with a broad focus based on the functional requirements. This allowed for design spirals and concepts which utilised the 6-3-5 method, brainwriting and $\mathrm{C}$-sketching for the generation and evaluation of multiple design solutions. Some of the products investigated included items such as an ergonomic monitor stand, environment monitor, integrated desks, and stationary exercise equipment. Sensing an untapped market, and its compatibility with the functional requirements, an ergonomic monitor stand for agile workplaces was chosen as a design path.

\subsection{Generation of DPs}

Design spirals utilising the 6-3-5 method, brainwriting and C-sketching allowed the compilation of a list of potential design parameters to satisfy the functional requirements.

\subsection{Morphological Matrix}

One of the methods used in design formulation is to list potential design parameters for every functional requirement. These can be arranged into a morphological matrix, which is used to formulate a solution using the listed design parameters. In this context, the three potential monitor stand products envisioned would employ an ergonomic height notification system and utilise the following elements in Table 6:

Product 1 - an autonomous stepper motor coupled to a ball screw. 
Product 2 - a manual hand crank and rack and pinion system to adjust the height.
Product 3 - a manual lever to adjust a truss or lattice support.

Table 6. Product Concept Morphological Matrix

\begin{tabular}{|c|c|c|c|c|c|}
\hline \multirow{2}{*}{ Functional Requirements } & \multicolumn{5}{|c|}{ Design Parameters } \\
\hline & $a$ & $b$ & $c$ & $d$ & $e$ \\
\hline $\begin{array}{l}\mathrm{FR}_{1121} \text { Increase Physical } \\
\text { Activity }\end{array}$ & Move Reminder & Hand Crank & Lever & & \\
\hline $\begin{array}{l}\mathrm{FR}_{1131} \text { Facililitate } \\
\text { Inclusiveness }\end{array}$ & Voice Activated & Facial Recognition & Low Pressure Buttons & Touch Screen & Maximise Leverage Arm \\
\hline $\begin{array}{l}\mathrm{FR}_{1212} \text { Keep Noise Between } \\
10 \mathrm{~dB}-50 \mathrm{~dB}\end{array}$ & Vibration Damping & Noise Insulation & Low Friction & Lubrication & \\
\hline $\begin{array}{l}\mathrm{FR}_{1213} \text { Optimise Luminosity } \\
\text { Levels 250lux - 500lux }\end{array}$ & Optical Angle & Reflection & Brightness & Reading Light & $\begin{array}{l}\text { Variable Brightness } \\
\text { Lightbulb }\end{array}$ \\
\hline $\mathrm{FR}_{1215}$ Improve Aesthetics & Cable Conduit & Internal Cable Routing & Cable Ports & & \\
\hline $\begin{array}{l}\mathrm{FR}_{1221} \text { Encourage Varying } \\
\text { Postures }\end{array}$ & Adjustable height & Angle Adjuster & $\begin{array}{l}\text { Periodical Height } \\
\text { Variations }\end{array}$ & & \\
\hline $\mathrm{FR}_{2 \mathrm{n}}$ Improve Safety & Bearing Guard & Pinch Point Protector & Moving Part Shield & & \\
\hline $\begin{array}{l}\mathrm{FR}_{221} \text { Integrate Dynamic } \\
\text { Workstation }\end{array}$ & Stepper Motor & Rack and Pinion & Belt Drive & Servo & Single-axis Slider \\
\hline $\mathrm{FR}_{231}$ Increase Ergonomics & Automated Adjustment & $\begin{array}{c}\text { Manual Adjustment } \\
\text { Handle }\end{array}$ & Translational Adjuster & & \\
\hline $\begin{array}{l}\mathrm{FR}_{31} \text { Decrease Maintenance } \\
\text { Requirements }\end{array}$ & No Metal to Metal Contact & Standardised Components & No Grease & Plastic Bearings & Single Shaft Assembly \\
\hline $\begin{array}{l}\mathrm{FR}_{312} \text { Increase Product } \\
\text { Lifespan }\end{array}$ & Anodise & Paint & Powder Coat & Material Selection & \\
\hline $\begin{array}{l}\text { FR } 321 \text { Improve Product } \\
\text { Utilisation }\end{array}$ & Discreet & Data Memory System & Unobtrusive Construction & & \\
\hline $\mathrm{FR}_{33 n}$ Reduce Complexity & Intutitive Design & Automated & Sensor & & \\
\hline
\end{tabular}

\begin{tabular}{l|lll} 
Product Concept & Product 1 & Product 2 & Product 3
\end{tabular}

\subsection{Application of the Independence Axiom}

The design parameters found in Table 6 for each concept (concept 1 being the ergonomic monitor stand) were found to satisfy either one or multiple functional requirements. As a result, it is wise to organise the FRs and DPs into a matrix to determine the level of coupling: uncoupled, decoupled and coupled designs. In Eq (1), Eq (2) and Eq (3), "X" denotes a FR-DP relationship and "O" the lack thereof. (Detailed DP hierarchy has been provided in Figure 14, Appendix.)

$\left[\begin{array}{l}F R_{1121} \\ F R_{1131} \\ F R_{1212} \\ F R_{1213} \\ F R_{1215} \\ F R_{1221} \\ F R_{211} \\ F R_{221} \\ F R_{231} \\ F R_{311} \\ F R_{312} \\ F R_{321} \\ F R_{3311}\end{array}\right]=\left[\begin{array}{lllllllllllll}X & O & O & O & O & X & O & O & O & O & O & O & O \\ O & X & O & O & O & O & O & O & O & O & O & O & X \\ O & O & X & O & O & O & O & X & O & O & O & O & O \\ O & O & O & X & X & X & O & X & X & O & O & X & O \\ O & O & O & O & X & O & X & O & X & X & O & O & O \\ X & X & O & X & X & X & X & X & X & X & O & O & O \\ O & O & O & O & O & O & X & X & O & X & O & O & O \\ O & O & X & O & O & O & O & X & X & O & O & X & O \\ O & O & O & O & O & O & O & X & X & X & O & O & O \\ O & O & O & O & O & O & X & O & O & X & O & O & X \\ O & O & O & O & O & O & O & O & O & O & X & O & O \\ O & O & O & O & O & O & O & O & O & O & O & X & X \\ O & X & O & O & O & O & O & O & O & O & O & O & X\end{array}\right]\left[\begin{array}{l}D P_{1121 a} \\ D P_{1131 b} \\ D P_{1212 b} \\ D P_{1213 \mathrm{e}} \\ D P_{1215 a} \\ D P_{1221 b} \\ D P_{211 a} \\ D P_{221 a} \\ D P_{231 a} \\ D P_{311 b} \\ D P_{312 a} \\ D P_{321 a} \\ D P_{3311 c}\end{array}\right]$



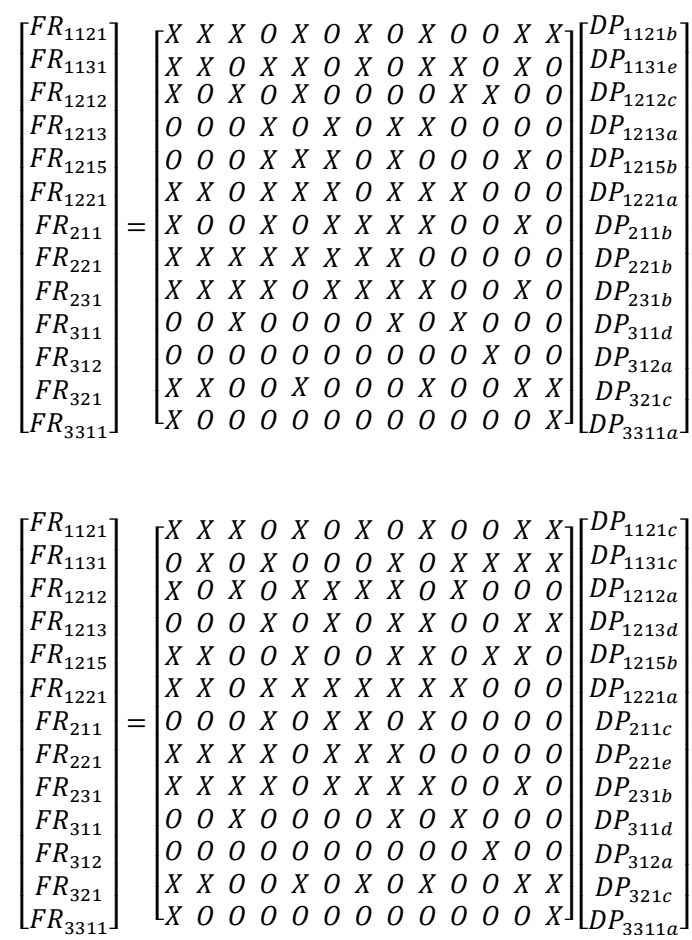

Through visual inspection of the matrices in Eq 1, Eq 2 and $\mathrm{Eq} \mathrm{3}$, it is apparent that concept 1 was the least coupled of the three and therefore warranted further development.

\subsection{Resolution of FR contradictions}

An attempt to solve the contradictions between the functional requirements used the TRIZ method. In this sense the physical contradictions were solved using separation in space or in time.

\subsection{Biologically Inspired Design}

Once the nature of the solution had been determined using morphological matrices and the Independence Axiom, it was required to determine the physical form of the solution. Nature has inspired humans to create new designs to solve tasks for millennia, so it was prudent to do the same in this context. The bodies of animals were excellent sources of inspiration for the physical form of the monitor stand as explained below:

\subsubsection{Flexible Cable Sheath: Venus basket sponge}

A lightweight, flexible sheath for monitor cables is used to discreetly organise the cables internally in a way that minimises obstruction (Figure 5). Inspiration comes from two levels: like the fibres of the sponge (Figure 6), the material of the sheath would be made of composites: a stiffer core surrounded by more flexible material would create a more lightweight, flexible structure as opposed to homogenous isotropic materials. The other level is the structure: the sponge body is not unlike a truss, so a sturdy frame for the cable can be created which saves material and reduces weight.

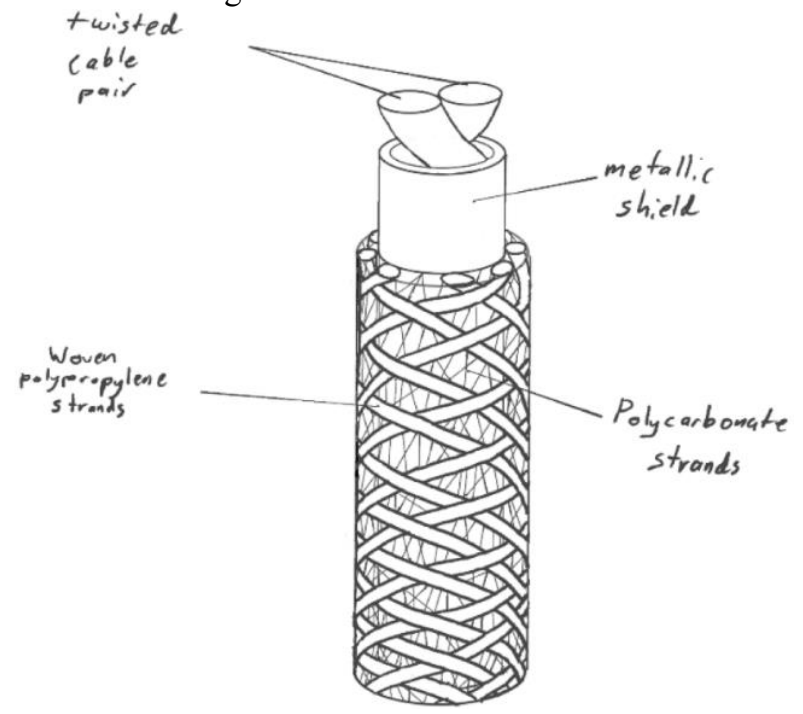

Figure 5. Cable Sheath Sketch

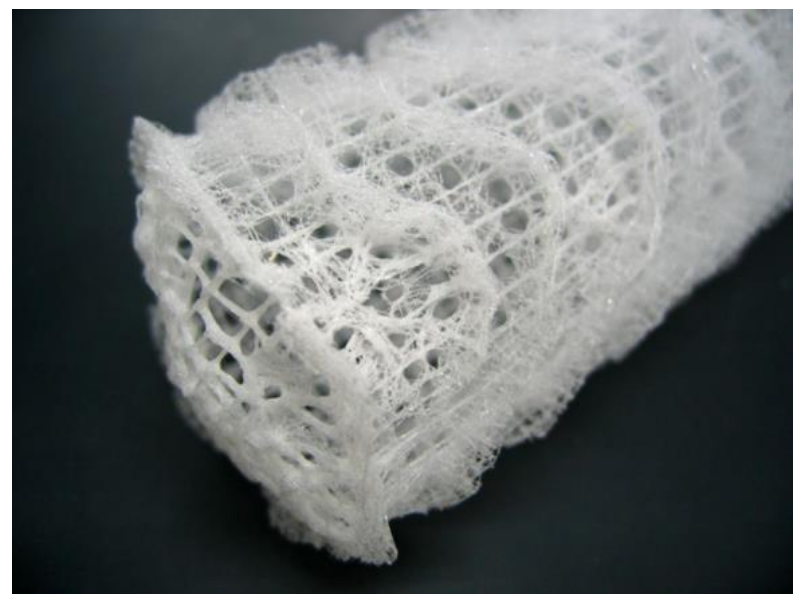

Figure 6. Cap of a Euplectella sp. glass sponge [6]

\subsubsection{Monitor Counterbalance and Weight Distribution: Squirrel}

A well-balanced monitor stand will exert less forces on the arms and base, which will make it more stable and increase its longevity. Squirrels (Figure 7) distribute their weight across different points on the tree to keep their centre of mass as close to in-line with the tree as possible and to prevent too much load being applied to any one point. This idea was applied to the stand: by making the arms attached to multiple points, or a continual connection as opposed to discrete points, to the central shaft and attaching a counterbalance to counter the weight of the monitors as shown in Figure 8. 




Figure 7. Squirrel Climbing a Tree [4]

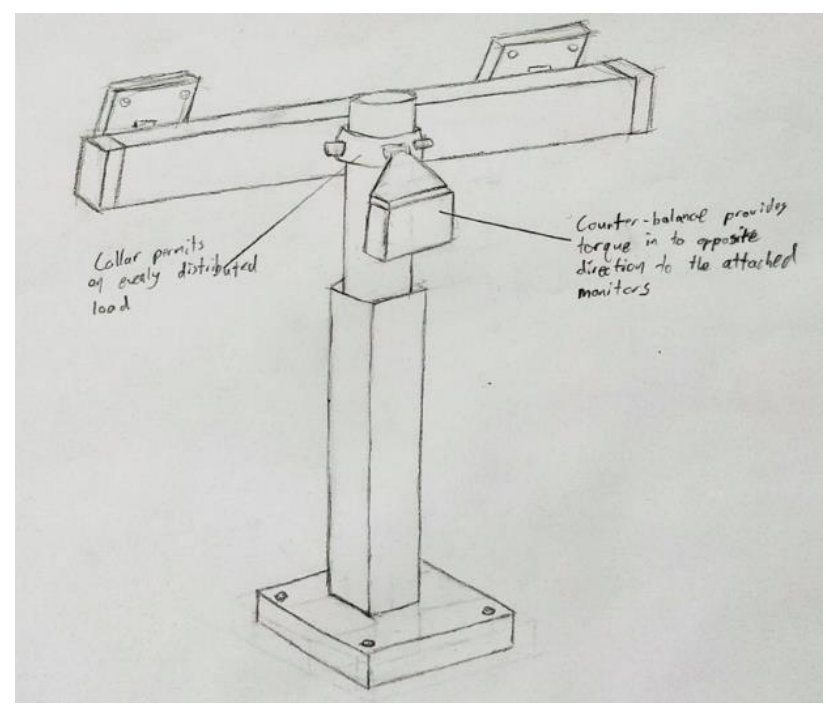

Figure 8. Counterbalance Sketch

\subsection{Application of the Information Axiom}

To determine the specific choices for each design parameter, the Information Axiom was used. This enabled the selection of the most robust solutions most likely to succeed at the lowest development cost. In this context, a probability density function following a Gaussian distribution was deemed the most suitable method to do this. For brevity, only two applications of the information axiom with regards to $\mathrm{FR}_{1212}$ and $\mathrm{FR}_{1213}$ have been provided.

As only $\mathrm{FR}_{1212}$ (Keep Noise Between $10 \mathrm{~dB}-50 \mathrm{~dB}$ ) and $\mathrm{FR}_{1213}$ (Optimise Luminosity Levels 250lux - 500lux) are quantifiable, they are the most obvious choice for assessment. Firstly, FR $_{1212}$ (Keep Noise Between 10dB $50 \mathrm{~dB}$ ) has been analysed to choose a method of product noise reduction, (Figure 9). Secondly, FR $_{1213}$ (Optimise
Luminosity Levels 250lux - 500lux) was assessed to define a suitable lighting solution (Figure 10).

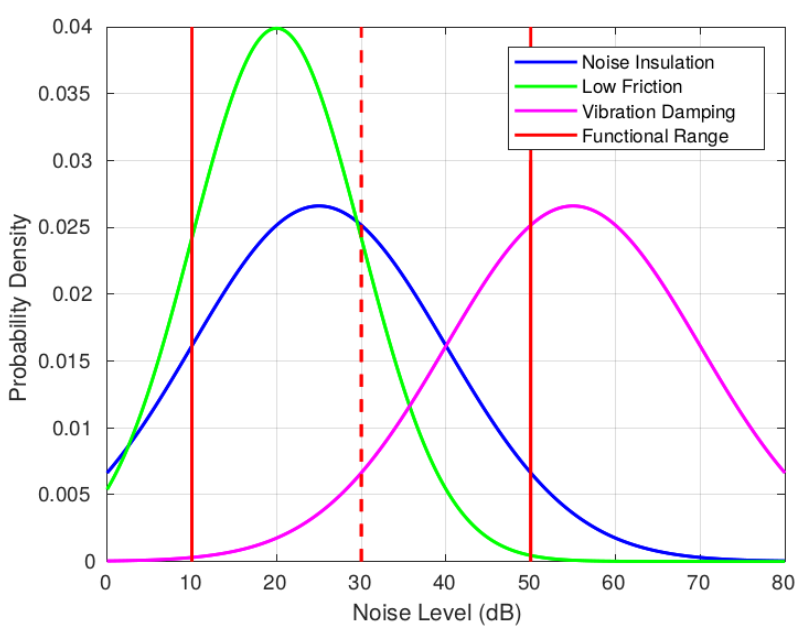

Figure 9. $\mathrm{FR}_{1212}$ Information Axiom Analysis

As shown in Figure 9, vibration damping is more suited for higher decibel noises. However, it does incapsulate a greater decibel range. This is because this system of insulation is typically used for large objects with fast moving speeds. Whilst reducing the vibration of the system is often favourable, it is not designed to move very quickly, and therefore not likely to make especially loud noises.

Low friction parts, as in those designed to minimise friction at all areas as much as possible, are effective to ensure that the product does not experience too much friction (and therefore produce noise) upon movement. Additionally, whilst this is certainly advantageous at the interfaces between multiple parts, not all surfaces need to be low friction. For example, noise reduction from moving the stand across the desk does not have appreciable benefits as it is something which is typically not done very often.

Noise insulation within the stand is feasible as only the internal moving parts create appreciable noise (e.g. stepper motor) and can be implemented more easily and cheaply in a localised area. It can also potentially cover a wider range of sound levels as stepper motors make a different amount of noise depending on load, therefore it is a robust option. 


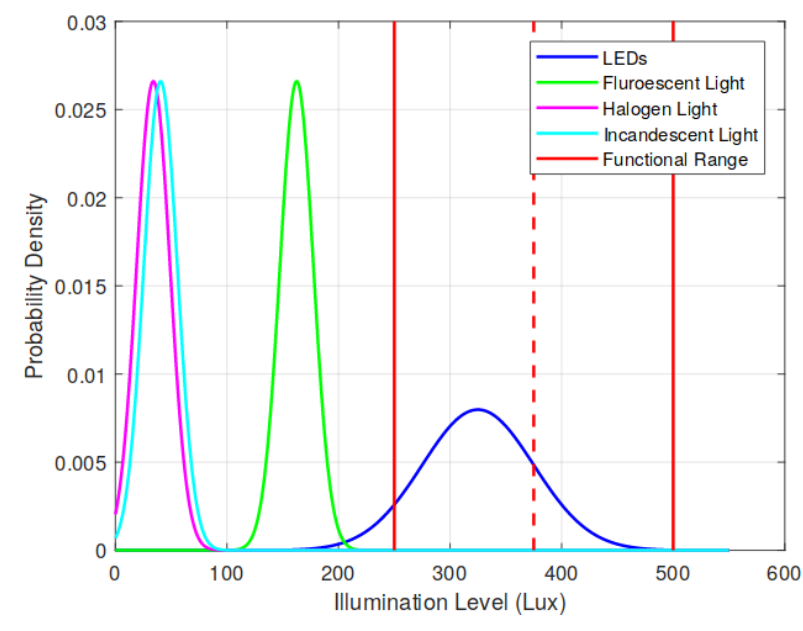

Figure 10. FR 1213 Information Axiom Analysis [7]

Figure 10 suggests that the fluorescent, halogen and incandescent lights considered for the concepts 2 and 3 were not bright enough to illuminate the work area adequately for a set power input. Whilst halogen lights are typically the brightest, it was not considered appropriate to supply the amount of power required to reach such levels of illumination. Therefore, since the light is low power (so not to draw too much power away from components such as the motor and the actual monitors) the variable LED lights that were chosen for Concept 1 conformed to the required range of the functional requirements.

Since the noise insulation and variable LED lights both largely fit inside the required ranges for their respective functional requirements and are adaptable enough to suit a range of values, it was determined that these were to most appropriate design parameters to choose for the design solution.

\section{Concept Visualisation}

An image showing an overall assembly of the final proposed product can be seen in Figure 11, with an exploded view provided in Figure 12.

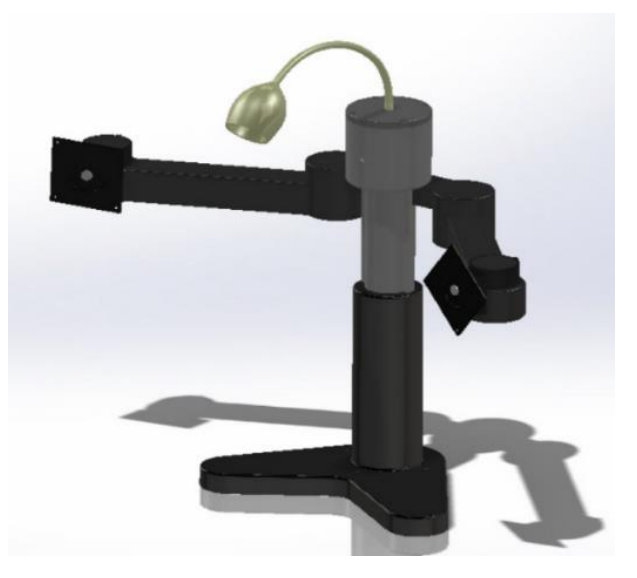

Figure 11. Rendering of Ergonomic Monitor Stand

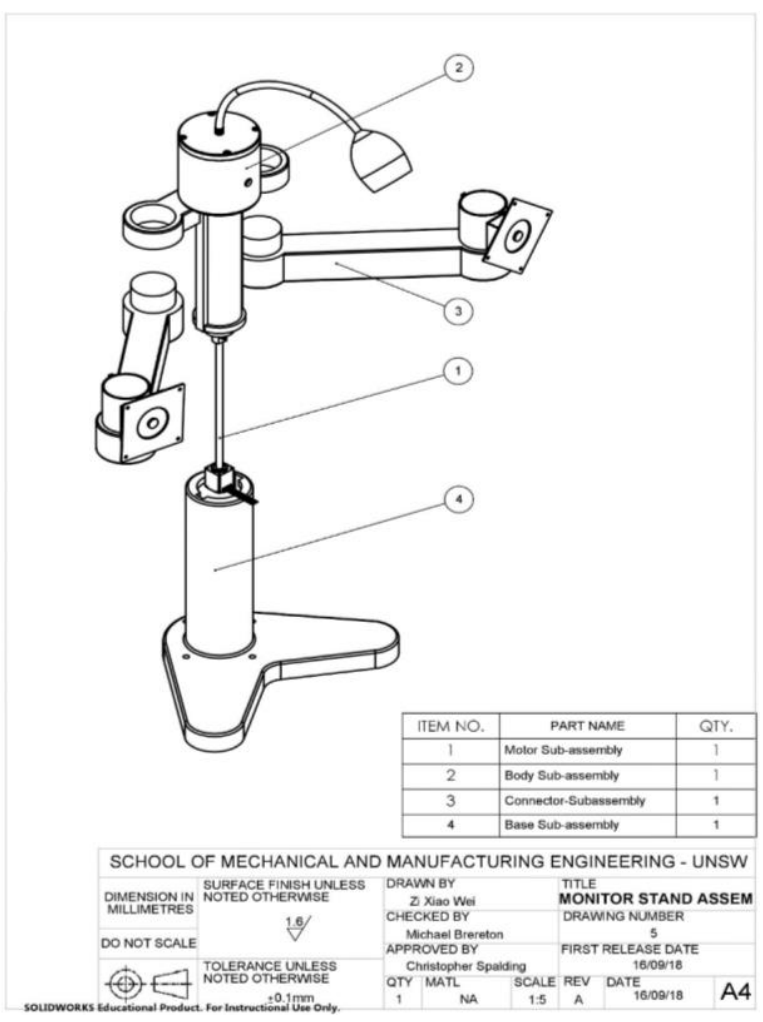

Figure 12. Exploded View of Monitor Stand Assembly with BOM

Labelled (1) in Figure 12 shows a threaded rod with stepper motor assembly which allows the monitor holders to automatically adjust height to a position most comfortable to the user using a camera with facial recognition software. The sensor also ensures that the monitor only turns on when the user is near, enhancing security and saving electricity which reduces the offices' ecological footprint. (2) is in reference to the body, which consists of the camera sensor housing/primary arm, a flexible lamp, (3) monitor mounts and (4) base subassembly.

\section{Conclusion}

Axiomatic design is an effective framework for the formulation of new concepts, especially for inexperienced engineering students. With proper research of the customer domain a wide variety of solutions can be developed with potential for originality and innovation. Use of this process culminated in the successful creation of a smart ergonomic monitor stand design with the ability to enhance the overall productivity of the agile office workplace.

\section{Reflection}

The process of axiomatic design was certainly useful in organising and channelling the creative forces of young engineers into useful solutions. Such a process allows an organised design path in a more coherent manner as 
opposed to random tangential directions which may prove to be irrelevant to the client brief.

We thank Dr Ang Liu for introducing us to this method of design thinking and granting us the opportunity to participate in this conference. We would also like to thank Daniel Setkiewicz, Michael Brereton and Nikola Medimeurac for their contributions to the design development.

\section{References}

This report is chiefly composed of content from the Office Optimisation Functional Design Report [8] and Agile Monitor Stand Conceptual Design Report [9].

1. Safe work australia, "Noise," [Online]. Available:https://www.safeworkaustralia.gov.au/noi se.

2. noao, "Recommended light levels," [Online]. Available:https://www.noao.edu/education/QLTkit/ ACTIVITY_Documents/Safety/LightLevels_outdoo r+indoor.pdf.

3. The University of Western Australia, "Computer workstation ergonomics," [Online].

Available:http://www.safety.uwa.edu.au/topics/phys ical/ergonomics/workstation.

4. A. Nature, "Silica skeleton is tough and stable," [Online].

Available:https://asknature.org/strategy/silica-

skeleton-is-tough-and-stable/\#jp-carousel-81472.

5. Beacon Lighting, [Online].

Available:https://www.beaconlightingtradeclub.com .au/media/Assets/Light_Output_Chart.pdf.

6. C. Spalding, D. Setkiewicz, A. Yarkov, Z. Wei, M. Brereton and N. Medimeurac, "Office Optimisation Functional Design Report,” UNSW, Sydney, 2018.

7. C. Spalding, D. Setkiewicz, A. Yarkov, Z. Wei, M. Brereton and N. Medimeurac, "Agile Monitor Stand Conceptual Design Report,” UNSW, Sydney, 2018.

8. V. Komalanathan and R. B. Thangavelu, "The effect of indoor office environment on the work performance, health and well-being of office workers," Journal of Environmental Health Science and Engineering, vol. 12, no. 1, 2014.

9. W. J. Fisk, P. N. Price and D. Faulkner, "Worker productivity and ventilation rate in a call center: Analyses of time-series data for a group of workers," 2002.
10. D. C. B. Simon Banbury, "Disruption of officerelated tasks by speech and office noise," British Journal of Psychology, vol. 89, no. 3, pp. 499 - 517, 1998. 


\section{Appendix}

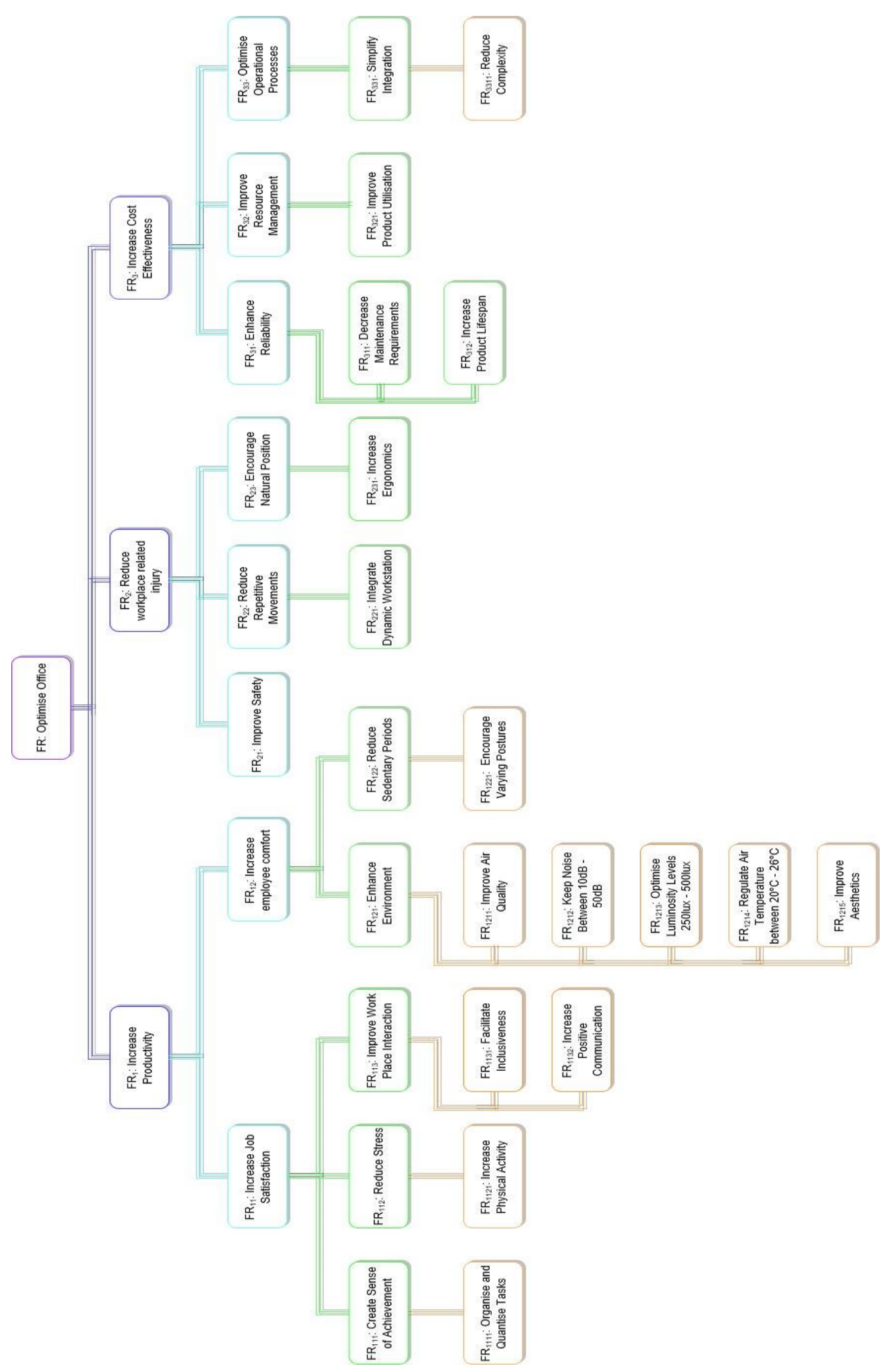

Figure 13. Functional Requirements Flow Chart 


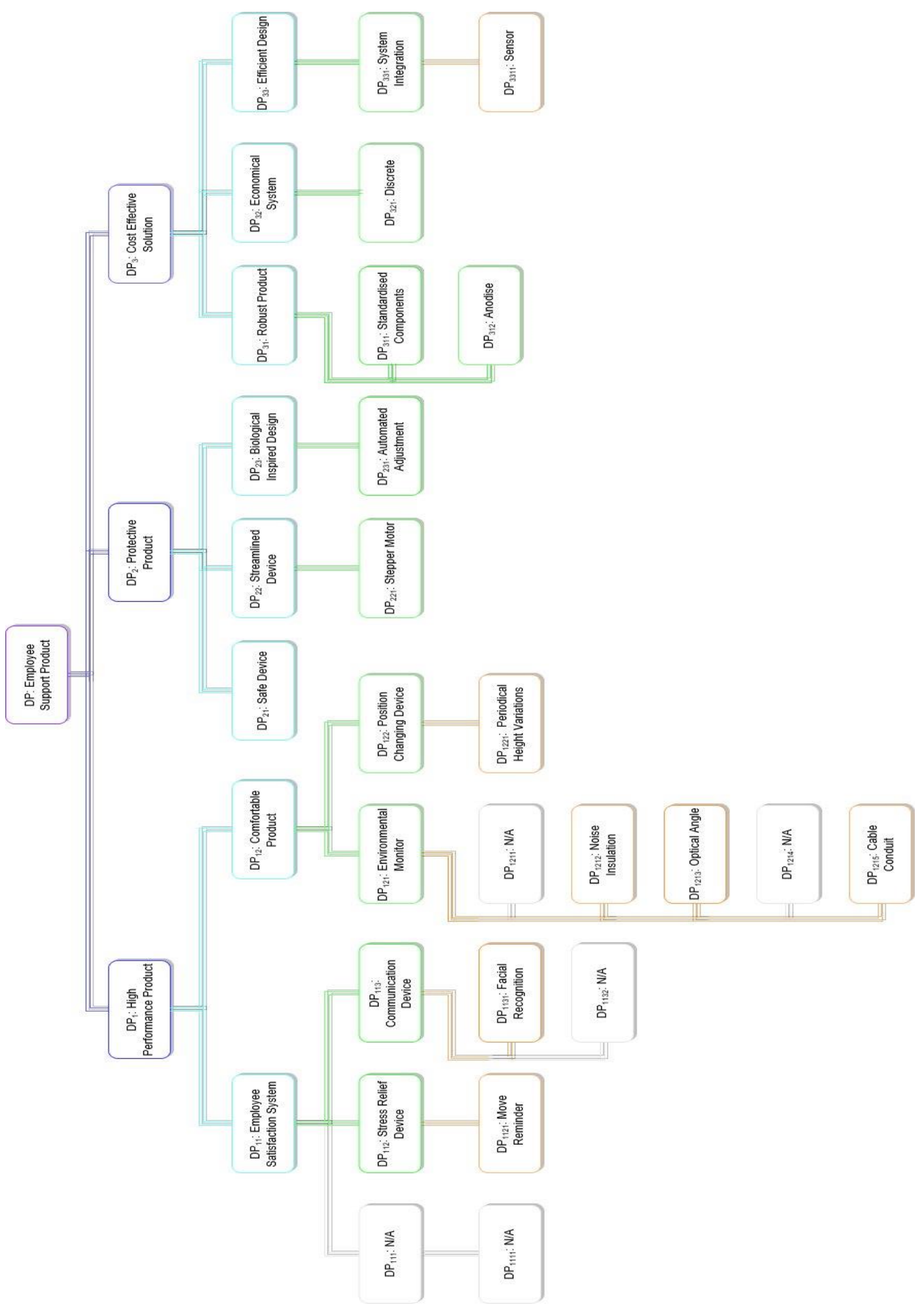

Figure 14. Design Parameter Hierarchy 